Yayın Geliş Tarihi: $\quad 08.03 .2016$

Yayın Kabul Tarihi: 15.04.2016

Online Yayın Tarihi: 13.07.2017
Dokuz Eylül Üniversitesi

İktisadi ve İdari Bilimler Fakültesi Dergisi

Cilt:32, Sayl:1, Yll:2017, ss. 29-56

\title{
Türk İmalat Sanayinde Risk ve Performans Arasındaki
}

\section{İlişki}

\author{
Seymur AĞAZADE1 Aykut KARAKAYA2 Selçuk PERÇİN3 \\ $\ddot{O} z$
}

Teorik yaklaşımlar risk ve performans ilişkinin doğasına yönelik farkl sonuçlar öngörürler. Geleneksel finans teorisi ve davranışsal firma teorisi bu ilişkiye yönelik olarak tartışmalı açıklamalar getirirler. Bu çalışmada Arellano ve Bover (1995) ile Blundell ve Bond (1998) tarafindan geliştirilen İki Aşamalı Sistem Genelleştirilmiş Momentler Metodu kullanılarak 2008-2013 dönemi için Türk Imalat Sanayinde risk ve performans ilişkisi incelenmiştir. Çalışmada risk göstergesi olarak toplam kaldıraç derecesi, faaliyet kaldıraç derecesi ve finansal kaldıraç derecesi kullanılmıştır. Performans değişkeni göstergeleri ise net kâr marjı, aktif kârlılık oranı ve öz sermaye kârlılık oranlarıdır. Panel veri tahmin sonuçları toplam kaldıraç derecesi veya finansal kaldıraç derecesi risk göstergesi olarak dikkate alındı̆̆ında performansın riski pozitif yönde etkilediğini göstermektedir. Risk göstergesi olarak faaliyet kaldıracı derecesi dikkate alındığında ise performansın riski negatif yönde etkilediği görülmüştür. Bu sonuç, toplam risk ve finansal risk söz konusu olduğunda geleneksel teorinin, buna karşın iş riski dikkate alındı̆̆ında ise davranışsal firma teorisini desteklemektedir.

Anahtar kelimeler: Risk, Performans, Türk Imalat Sanayi.

JEL Sinıflandirma Kodları: G30, L60.

\section{The Relationship Between Risk and Performance in Turkish}

\section{Manufacturing Industry}

\begin{abstract}
Theoretical approaches make different prediction related to the nature of the relationship between risk and performance. Traditional finance theory and behavioural firm theory give controversial explanation about this relationship. Using Two Stage System Generalized Moment Method proposed by Arellano and Bover (1995) and Blundell and Bond (1998) this paper investigates risk and performance relationship in Turkish Manufacturing Industry for the period from 2008 to 2013. The degrees of total leverage, operating leverage and financial leverage are used as risk indicators. Net profit margin, return on assets, return on equity are performance variables. Panel estimation results demonstrate that performance effects risk positively when degree of total leverage or financial leverage is used as risk indicator and negatively when degrees of operating leverage is used as risk indicator. These results support the traditional finance theory when total risk or financial risk is taken into account and behavioural firm theory when operational risk is considered as risk proxies.
\end{abstract}

Keywords: Risk, Performance, Turkish Manufacturing Industry.

JEL Classification Codes: G30, L60.

1 Doç.Dr., Recep Tayyip Erdoğan Üniversitesi, İktisadi ve İdari Bilimler Fakültesi, İktisat Bölümü, seymur.agazade@erdogan.edu.tr.

2 Yrd.Doç.Dr., Recep Tayyip Erdoğan Üniversitesi, İktisadi ve İdari Bilimler Fakültesi, İşletme Bölümü, aykut.karakaya@erdogan.edu.tr.

3 Prof.Dr.,Karadeniz Teknik Üniversitesi, İktisadi ve İdari Bilimler Fakültesi, İşletme Bölümü, selcukpercin@yahoo.com. 


\section{GİRIŞ}

\section{S.AĞAZADE - A.KARAKAYA - S. PERÇIN}

Risk ve getiri ilişkisi çok faklı alanda söz konusu ve farklı boyutlara sahip olabileceğinden dolayı konuya ilişkin teorik farklılıkların yanı sıra deneysel çalışmalarda da tutarlılık göstermeyen sonuçlar mevcuttur. Teorik ve deneysel farklılıklar risk ve getiri kavramlarının farklı tanım ve ölçülmelerinden kaynaklanabileceği gibi, ölçümlerin farklı alanlarda yapılmış olmasından da kaynaklanabilir. Geleneksel finans teorisinin risk ve performans arasında öngördüğü pozitif ilişkinin aksine Bowman'ın (1980 ve 1984), bu ilişkinin ağırlıklı olarak negatif yönlü olabileceğine ilişkin sonuçlar bu alanda ilgi uyandırıcı olmuştur.

Kahneman ve Tversky (1979) tarafından geliştiren beklenti teorisi ve Cyert ve March'ın (1963) davranışsal firma teorisi de risk ve performans ilişkisinin negatif yönlü olabileceğine teorik temel ve Bowman'ın (1984) sorunlu firmaların risk arama eğilimine teorik çerçeve sunmuştur. Şöyle ki, örneğin beklenen ya da arzulanan performans düzeyine ya da endüstride bulunan firmaların veya öncü firmaların ortalama performans düzeyine göre daha düşük performansa sahip olmalarının, firmaların iflastan kaçınma eğilimiyle daha riskli faaliyetlere girmekte istekli davranmalarına neden olduğu ileri sürülmüştür.

Bromiley (1991), risk ve performansa ilişkin mevcut literatürde çoğunlukla aynı döneme ait getiri değişkenliği ile getiri arasındaki ilişkinin incelendiğini ifade etmiştir. Buna göre, değişkenlerin aynı döneme ait değerlerinin kullanılması performans tarafından etkilenen risk alma düzeyi ile risk alma düzeyinden etkilenen performans arasındaki ayırımı belirsizleştirmektedir. $\mathrm{Bu}$ nedenle Bromiley (1991), geçmiş dönem performansının cari dönemde risk alma tutumuna etkisini ve bunun yanı sıra 
alınan risk düzeyinin sonraki dönemin performansına etkisini modellemeğe çalışmıştır.

Bu çalışmada da Bromiley (1991) modeli esas alınarak 2008-2013 döneminde Türkiye İmalat Sanayi endüstri kollarında performansın risk alma tutumu üzerindeki etkisi incelenmeye çalışılmıştır. $\mathrm{Bu}$ doğrultuda kârlılıkların kaldıraç dereceleri üzerine etkileri İki Aşamalı Sistem Genelleştirilmiş Momentler Metodu ile tahmin edilmiştir. Sonuçta, kârlılıkların kaldıraç dereceleri üzerine etkilerinin tek düze olmadığg bulunmuştur. Çalışma beş bölümden oluşmaktadır. İkinci bölümde risk ve performans arasındaki ilişki teorik açıdan ele alınmış, üçüncü bölümde veri, değişkenler ve tahmin yöntemi sunulmuş, dördüncü bölümde tahmin sonuçları verilmiştir. Son bölümde ise sonuç ve değerlendirmelere yer verilmiştir.

\section{RISKK VE PERFORMANS İLIŞKISINIDE TEORIKK TARTIŞMA}

Finans teorisinde risk ve getiri arasında pozitif ilişki (tradeoff ) merkezi bir yere sahiptir (Fletcher, 2000: 244). Bu yaklaşım firmaların riskten kaçınma eğilimine sahip olduklarını varsayar ve daha fazla risk almanın daha yüksek getiriye, daha düşük risk almanın da daha düşük getiriye eşlik ettiğini kabul eder (Fisher ve Hall, 1969: 82). Fakat riskin getiri varyansı şeklinde ifade edildiği 85 endüstriye ait çok sayıda firma için Bowman (1980), risk ile getiri arasında negatif ilişki olduğunu bulmuş ve bu negatif ilişki Bowman paradoksu olarak adlandırılmıştır. Klasik finans teorisinin öngördüğü risk ve getiri arasındaki pozitif yönlü ilişki ve kabul edilen riskten kaçınma eğilimine karşın Bowman’a (1980) göre birimler risk arama eğilimine de sahip olabilecekleri için risk getiri ilişkisi negatif yönlü olması mümkündür. 


\section{S.AĞAZADE - A.KARAKAYA - S. PERÇIN}

Kahneman ve Tversky (1979) tarafından geliştiren beklenti teorisi ise, karar alma süreçlerinde insanların beklenen fayda teorisinin ekonomik davranışlara dair sonuçlarıyla tutarlı olmayan şekilde tercihlerde bulunduklarını ileri sürer ve risk ve performans ilişkisine dair daha farklı sonuçlara varır. Bilindiği gibi, beklenen fayda teorisi belirsizlik ortamında muhtemel sonuçların gerçekleşmesini olasılık dağılımı şeklinde ifade eder. Rasyonel davranış varsayımına dayanan bu teoriye göre insanlar, sonuçların olasılık dağılımına ve her bir sonuçtan elde edilebilecek faydaya göre tarafsizca karar verirler. Kahneman ve Tversky'nin (1979) beklenti teorisine göre ise insanlar kesin sonuçlara nispeten olası sonuçlara daha az ağılık verirler. Bu durum, kesinlik (certainity) eğilimi olarak adlandırılır. Kesin kazançlarda yani yöneticiler performansın referans düzeyden daha yüksek olduğunu düşündüklerinde riskten kaçınma ve kesin kayplarda ise yani yöneticiler performansin referans düzeyden daha düşük olduğunu düşündüklerinde risk arama şeklinde ortaya çıkmaktadır. Bunun sonucunda, insanlar kesin kazançları olası kazançlara ve olası kayıpları kesin kayıplara tercih ederler. Risk alma eğilimindeki bu farklılaşma risk ve performans ilişkisinin değişmesine neden olmaktadır. Şöyle ki, düşük performans yöneticilerin risk arama eğilimine sahip olmalarına neden olurken risk ve performans arasında negatif yönlü ilişkiye neden olmaktadır. Aksine performansin referans düzeyine göre yüksek olması yöneticilerin riskten kaçınma eğilimine neden olmaktadır.

Beklenti teorisi risk getiri ilişkisinin değerlendirmesini endüstri medyanı gibi sabit bir referans noktasına göre yapar. Gooding, Goel ve Wiseman (1996) ise, sabit bir referans noktasının kabul edilmesine itiraz ederler. Araştırmacılara göre endüstri performansından bağımsız olarak firmaların referans noktası zamana göre değişir. Ayrıca firmalar genellikle endüstri 
medyan düzeyinden daha yüksek olduğunu düşündükleri bir referans noktasına göre değerlendirme yaparlar.

Aynı problem, farklı şekillerde ifade edildiğinde davranışta ortaya çıkan değişme, seçimlerin ifade ediliş biçimlerinin de insanların kararlarında etkili olabileceğini gösterir. Kahneman ve Tversky (1979) tarafindan yalıtım (isolation) etkisi sonradan ise çerçeve etkisi şeklinde adlandırılan bu durum, aynı seçenek başka biçimlerde ifade edildiğinde insanların tutarsız tercihlerde bulunduklarını ifade etmek için kullanılır. Karar alıcıların risk alma tutumları kararlarının sonuçlarına ilişkin tahminlerinin yanı sıra mevcut durumlarından da etkilenir. Kazanç ve kayılarını, mevcut durumlarından farklı olarak beklenilen veya istenilen bir düzeye göre de değerlendirebilirler (Kahneman ve Tversky, 1979: 263). Referans noktas1 olarak adlandırılan bu düzey beklenti teorisinde önemli bir yere sahiptir. Performansın referans noktasına göre düzeyi karar alıcıların risk düzeyine ilişkin değerlendirmelerini ve dolayısıyla alınan risk düzeyini etkiler. Aynı probleme ilişkin farklı referans noktalarının kullanılması doğal olarak değerlendirme sonuçlarını ve risk düzeyini de farklılaştırır.

Risk ve performans ilişkisinin davranışsal firma teorisi, temel olarak Cyert ve March'a (1963) dayanmaktadır. Bu teoride firmaların, aralarında çok sayıda çatışmanın olduğu bir dizi birimin ortaklığından oluşan büyük sistemler oldukları ve belirsizlik altında faaliyet gösterdikleri varsayılır. Firma yöneticileri performanslarını değerlendirirken performansa ilişkin arzuladıkları düzeyi (aspiration level) dikkate alırlar. Arzulanan düzeye karşın beklenen performans düzeyi karar birimlerinin risk alma eğilimlerini etkilemektedir. Eğer beklenen performans düzeyi arzulanan düzeyden daha düşük ise yöneticiler beklenen performansı yükseltmeye yönelik arayışlara girerler (Bromiley, 1991: 39). 


\section{S.AĞAZADE - A.KARAKAYA - S. PERÇİN}

Risk alma tutumuna ilişkin davranışsal yaklaşımlarda gevşeklik (slack), arzulama (aspiration; geleceğe yönelik arzulanan başarı düzeyi) ve performans gibi değişkenler de yöneticilerin riske ilişkin kararlarını etkiler. Örneğin, yöneticiler düşük ve yüksek gevşeklik durumunda daha yüksek risk alma eğilimi taşırlar. Düşük gevşeklik düzeyinde firmanın hayatta kalması için daha yüksek risk almaları gerekir. Benzer şekilde, yüksek gevşeklik düzeyinde de kayıpların önemli bir tehdit oluşturmayacağ 1 düşünülür ve tehditlerin olumsuz sonuçlarını kolaylıkla karşılayabilecekleri kaynaklara sahip olduklarından daha yüksek risk alırlar. Yöneticilerin hedeflerini veya başarılmak istenen performans düzeyini ifade etmek için kullanılan arzulanan performans düzeyi de yöneticilerin kararlarında etkili olur. Arzulanan düzeyin üzerinde elde edilen sonuçlar başarı olarak değerlendirilir ve yöneticilerin davranışlarını temellendirdikleri kuralları sürdürme eğilimlerini güçlendirir. Arzulanan düzeyin altındaki sonuçlar ise başarısızlık olarak değerlendirilir ve yöneticileri kurallarını değiştirme yönünde cesaretlendirir. Yöneticilerin performansa ilişkin değerlendirmeleri de risk alma tutumlarını etkiler. Şöyle ki, yöneticiler kendilerini belirli bir performans hedefinin üzerinde değerlendirdiklerinde başarısız olma olasılığını düşük varsayarlar veya gevşeklik dolayısıyla bu olasılığı ihmal ederler ve daha yüksek risk alma eğilimi gösterirler. Benzer şekilde, hedef düzeyinin altına düşüldüğünde ise hedef performans düzeyini gerçekleştirme olasılığını artırmak için daha yüksek risk alma eğilimi gösterirler (Bromiley, 1991: 40).

Stratejik davranış da performans sonuçlarını etkiler ve firma performansının risk - getiri profilini şekillendirir. Bu davranış şekli, sanayi dalının belirli karakteristik özelliği, rekabetçi yapı ve firmaların bu çevresel koşullara cevap verebilme kabiliyetinin bir sonucu olarak ortaya çıkar (Andersen, Denrell ve Bettis, 2007: 423). 
Deephouse ve Wiseman (2000), risk ve getiri ilişkisinin referans temelli yönetici tercihlerine göre açıklayan modellerin, ilişkinin alternatif birçok başka açıklamalarını ihmal ettiğini ileri sürer. Bunun yanı sıra, risk tercihinin performansta önemli bir rol oynaması gerektiğine ilişkin geleneksel stratejik yönetim varsayımına dayanan, yüksek risk ile düşük getiriyi ilişkilendiren argümanların güçlü teorik temellerinin olmadığını belirtir. $\mathrm{Bu}$ nedenle, risk almayı yönetici tercihleri temelinde açıklarken vekalet teorisi (yönetici ve sahiplerin farklı risk alma eğilimine sahip olduğunu ileri süren görüş), örtük anlaşma teorisi (implicit contracts theory, gelir akımı belirsizliğinde artışın pay sahiplerine devam eden patronajlarından dolayı (stakeholders) bir prim ödemesi ile sonuçlanabileceğini ileri süren görüş) ve makroekonomik duruma ilişkin farklılıkların da dikkate alınması gerektiğini ifade eder.

Bowman paradoksu istatistiksel hata ile de açıklanmaktadır. Bu görüşe göre, zaman spesifik risk getiri ilişkisi ile ilişkide zamanla ortaya çıkan kaymaları birbirinden ayırt etmek mümkün olamadığından, risk ve getiri ilişkisinin negatif olması kusurlu istatistiksel yöntemlerden ve modelleme hatalarından kaynaklanır (Andersen, Denrell ve Bettis, 2007: 407).

Yukarıda ifade edilen risk ve performansa ilişkin çok sayıda farklı görüşten de anlaşıldığı gibi konu teorik uzlaş1dan oldukça uzaktır. Değişkenler arasında nedenselliğin yönüne ilişkin görüş ayrılıkları vardır. Bunun yanı sıra, risk ve performans korelasyonunun yüksek risk - yüksek performans ve yüksek risk - düşük performans şeklinde olduğu da tartışmalıdır. Buradan hareketle bu çalışmada, performansın risk alma tutumu üzerindeki etkisi Türkiye imalat sanayisinin 24 endüstri kolu örneğinde araştırılmaya çalışılmıştır. 


\section{S.AĞAZADE - A.KARAKAYA - S. PERÇİN \\ 3. VERİ, DEĞİŞKENLERİN TANIMLARI VE METODOLOJİ}

Bu çalışmada, NACE Rev.2 sınıflamasına göre Türk İmalat Sanayi endüstri kollarında risk ve performans ilişkisi panel veri yöntemi ile incelenmiştir. Analiz, yıllık verilerle gerçekleştirilmiş ve veriler Türkiye İstatistik Kurumu'nun internet adresinden derlenmiştir. 144 gözlemden oluşan veri seti 24 endüstri kolunu ve 2008-2013 yıllarını kapsamaktadır.

Tablo 1'de Türk İmalat Sanayi firmalarının endüstrilere göre dağılımı sunulmuştur. Dağılıma bakıldığında gida, tekstil, metalik olmayan mineraller, giyim ve fabrikasyon metal ürünleri endüstrilerinde faaliyet gösteren firmaların toplam imalat sanayi firmalarının yarısından fazlasını oluşturduğu görülmektedir. Söz konusu bu endüstriler daha ziyade teknolojinin görece daha düşük düzeyde kullanıldığı geleneksel sanayiyi temsil etmektedir.

Tablo 2'de ise çalışmanın değişkenleri toplu biçimde sunulmuştur. Literatürde firmaların performansı finansal veya finansal olmayan göstergelerle ölçülmektedir. Bunlardan daha yaygın olanı finansal göstergelerdir. Finansal göstergelerden net kar marjının (Hoque ve James, 2000; Fraquelli ve Vannoni, 2000; Obiyo and Lenee 2011; Yasser, Entebang ve Mansor, 2011; Al Manaseer vd., 2012), aktif karlılığının (Ittner ve Larcker, 1997; Murphy, 2001; Park, Yang, Shi, Jiang, 2009; Karaca ve Ekşi, 2012; Chari, Chen ve Dominguez, 2012) ve öz sermaye karlılığının (Hansen ve Wernerfelt, 1989; Core, Holthausen ve Larcker, 1999; Murphy, 2001; Ittner, Larcker ve Randall, 2003; Lin, 2011) performans göstergesi olarak ele alındığı çalışmalara literatürde sıklıkla karşılaşılmaktadır. Ölçüm objektifliği ve kullanım yaygınlığı açısından bu çalışmada net kar marjı, aktif karlılık oranı ve öz sermaye karlı1ık oranı performans göstergesi olarak belirlenmiştir. 
Tablo 1. Endüstri Kollarındaki Firmaların Dağılımı

\begin{tabular}{|c|c|c|c|}
\hline $\begin{array}{l}\text { Endüstri } \\
\text { Kodu }\end{array}$ & Endüstri Kolu & Sayı & $\%$ \\
\hline 10 & G1da Ürünlerinin İmalatı & 2.682 & 13,13 \\
\hline 11 & İçeceklerin İmalatı & 159 & 0,78 \\
\hline 12 & Tütün Ürünlerinin İmalatı & 66 & 0,32 \\
\hline 13 & Tekstil Ürünlerinin İmalatı & 2.778 & 13,59 \\
\hline 14 & Giyim Eşyalarının İmalatı & 1.719 & 8,41 \\
\hline 15 & Deri ve İlgili Ürünlerin İmalatı & 303 & 1,48 \\
\hline 16 & $\begin{array}{l}\text { Ağaç, Ağaç Ürünleri ve Mantar Ürünleri İmalatı (Mobilya } \\
\text { Hariç) }\end{array}$ & 378 & 1,85 \\
\hline 17 & Kağıt ve Kağıt Ürünleri İmalatı & 561 & 2,74 \\
\hline 18 & Kayıtlı Medyanın Basılması ve Çoğaltılması & 231 & 1,13 \\
\hline 19 & Kok Kömürü ve Rafine Edilmiş Petrol Ürünleri İmalatı & 87 & 0,42 \\
\hline 20 & Kimyasalların ve Kimyasal Ürünlerin İmalatı & 894 & 4,37 \\
\hline 21 & $\begin{array}{l}\text { Temel Eczacılık Ürünleri ve Eczacılığa İlişkin Malzemelerin } \\
\text { İmalatı }\end{array}$ & 237 & 1,16 \\
\hline 22 & Kauçuk ve Plastik Ürünlerin İmalatı & 1.257 & 6,15 \\
\hline 23 & Diğer Metalik Olmayan Mineral Ürünlerin İmalat & 1.773 & 8,67 \\
\hline 24 & Ana Metal Sanayi & 1.230 & 6,02 \\
\hline 25 & $\begin{array}{l}\text { Fabrikasyon Metal Ürünleri İmalatı (Makin eve Teçhizat } \\
\text { Hariç) }\end{array}$ & 1.467 & 7,18 \\
\hline 26 & Bilgisayarların, Elektronik ve Optik Ürünlerin İmalatı & 201 & 0,98 \\
\hline 27 & Elektrikli Teçhizat İmalatı & 723 & 3,54 \\
\hline 28 & Başka Yerde Sınıflandırılmış Makin eve Ekipman İmalatı & 1.254 & 6,14 \\
\hline 29 & Motorlu Kara Taşıtı, Treyler ve Yarı Treyler İmalatı & 900 & 4,40 \\
\hline 30 & Diğer Ulaşım Araçlarının İmalatı & 288 & 1,41 \\
\hline 31 & Mobilya İmalatı & 570 & 2,79 \\
\hline 32 & Diğer İmalatlar & 534 & 2,61 \\
\hline \multirow[t]{2}{*}{33} & Makine Ekipmanların Kurulumu ve Onarımı & 138 & 0,67 \\
\hline & İmalat Sanayi & 20.430 & 100 \\
\hline
\end{tabular}

Literatürde firmaların risk göstergesi olarak faaliyet kaldıracı derecesi (Lev, 1974; Gershon, 1984; Mandelker ve Rhee 1984), finansal kaldıraç derecesi (Gershon, 1984; Mandelker ve Rhee 1984; O’Brien ve Vanderheiden 1987; Dugan ve Shriver 1992) ve toplam kaldıraç derecesi (Lord, 1998; De Young ve Roland, 1999) kullanılmaktadır. Sektörel bilanço ve gelir tablolarından yıl kaybı olmadan ve objektif biçimde hesaplanabildiğinden bu çalışmada risk göstergesi olarak faaliyet kaldıracı derecesi, finansal kaldıraç derecesi ve toplam kaldıraç derecesi seçilmiştir. Faaliyet kaldıracı derecesi faaliyet, finansal kaldıraç derecesi finansal ve 


\section{S.AĞAZADE - A.KARAKAYA - S. PERÇIN}

toplam kaldıraç derecesi de toplam riski temsil etmektedir. Kaldıraç dereceleri ve risk arasındaki bağlantılar aşağıda açıklanmıştır.

Tablo 2. Araştırma Değişkenleri

\begin{tabular}{|c|c|c|c|}
\hline & \multicolumn{2}{|l|}{ Değişkenler } & Açıklamalar \\
\hline \multirow{3}{*}{ 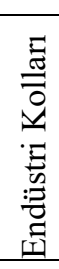 } & \multirow[t]{3}{*}{ RİSK } & Faaliyet Kaldıracı Derecesi - FKD & $\begin{array}{l}\text { (Brüt Satış Karı/Faiz ve } \\
\text { Vergi Öncesi Kar) }\end{array}$ \\
\hline & & Finansal Kaldıraç Derecesi - FíKD & $\begin{array}{l}\text { (Faiz ve Vergi Öncesi Kar } \\
\text { /Olağan Kar) }\end{array}$ \\
\hline & & Toplam Kaldıraç Derecesi - TKD & $\begin{array}{l}\text { (Brüt Satış Karı/ Olağan } \\
\text { Kar) }\end{array}$ \\
\hline \multirow{3}{*}{ 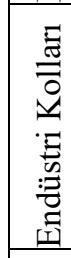 } & \multirow[t]{3}{*}{ PERFORMANS } & Net Kar Marj1 - NKM & $\begin{array}{ll}\text { (Net Dönem Karı/Net } \\
\text { Satışlar) }\end{array}$ \\
\hline & & Aktif Karlılık Oranı - AKO & $\begin{array}{l}\text { (Net Dönem Karı/Aktif } \\
\text { Toplamı) }\end{array}$ \\
\hline & & Öz Sermaye Karlılık Oranı - ÖSKO & $\begin{array}{ll}\text { (Net Dönem Karı/Öz } \\
\text { Sermaye) }\end{array}$ \\
\hline \multirow{3}{*}{ 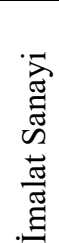 } & \multirow[t]{3}{*}{ PERFORMANS } & Net Kar Marji & $\begin{array}{l}\text { (Net Dönem Karı/Net } \\
\text { Satışlar) }\end{array}$ \\
\hline & & Aktif Karlılık Oranı & $\begin{array}{l}\text { (Net Dönem Karı/Aktif } \\
\text { Toplamı) }\end{array}$ \\
\hline & & Öz Sermaye Karlılık Oranı & $\begin{array}{l}\text { (Net Dönem Karı/Öz } \\
\text { Sermaye) }\end{array}$ \\
\hline
\end{tabular}

Firmaların karşılaştığı riskler iş riski ve finansal risk olarak ifade edilir. İş riski, firmanın faaliyette bulunduğu işle ilgili olup ürünlerin satış fiyatındaki değişme ile sabit faaliyet giderinden kaynaklanır. Sabit faaliyet giderinin düzeyi firmanın iş riskini gösterir. Firmanın sabit faaliyet gideri ile iş riski paralel hareket etmektedir. Söz konusu sabit faaliyet giderlerinin firma giderleri içerisindeki düzeyini ölçen göstergeye faaliyet kaldıracı derecesi denir. Faaliyet kaldıracı derecesi arttığında firmanın iş riski artar, tersi durumda iş riski azalır. Gelir tablosundan yola çıkarak faaliyet kaldıracı derecesi toplam katkı payının faaliyet kârına oranı olarak hesaplanır. Eğer, toplam katkı payına ulaşılamıyorsa, toplam katkı payı yerine brüt satış kârı kullanılarak faaliyet kaldıracı derecesi hesaplanabilir.

Finansal risk ise, firmanın faaliyetlerini sürdürürken borçlanmaya başvurması durumunda, borç için yapılan faiz ödemelerinden ve imtiyazlı 
hisselere ödenen kâr paylarından kaynaklanan sabit finansman giderleridir. İmtiyazlı hisselere ödenen kâr paylarına ulaşılamadığı durumda ödenen faizlerin sabit finansman giderini oluşturduğu varsayılır. Bu faiz ödemeleri borç sözleşmesiyle belirlendiğinden firma faaliyet hacminden bağımsızdır ve firmanın sabit finansman gideridir. Söz konusu sabit finansman gideri finansal riski oluşturur. Sabit finansman gideri yüksek olan firmaların finansal riski yüksektir. Finansal riskin ölçülmesinde finansal kaldıraç derecesi kullanılır. Finansal kaldıraç derecesi arttığında finansal risk artar, tersi durumda finansal risk düşer. Gelir tablosundan finansal kaldıraç derecesi faiz ve vergi öncesi kârın vergi öncesi kâra oranı biçiminde hesaplanır. Eğer olağan dışı gelir ve giderlerin bulunması halinde, dönemler itibariyle karşılaştırma yapabilmek amacıyla vergi öncesi kâr yerine olağan kârın kullanımı daha doğru olacaktır.

Sabit faaliyet gideri ve sabit finansman gideri toplamı firmanın toplam sabit giderini verir. Sabit giderler de firmanın toplam risk düzeyini gösterir. Başka bir anlatımla, faaliyet riski ve finansal risk birleştirildiğinde firmanın toplam riskine ulaşılır. Toplam riski ölçmek için toplam bileşik kaldıraç derecesi kullanılır. Gelir tablosundan yararlanılarak toplam kaldıraç derecesi toplam katkı payının vergi öncesi kâra oranı şeklinde hesaplanır. Diğer yandan, faaliyet kaldıracı derecesi ile finansal kaldıraç derecesinin çarpımı toplam kaldıraç derecesi yani toplam riski verir.

Araştırmada panel veri tahmin yöntemi kullanılmıştır. Panel veri analizinin en temel yöntemi Havuzlanmış En Küçük Kareler (HEKK) olmasına rağmen hata terimi ve bağımsız değişkenler arasında ilişskinin varlığında, HEKK ile tutarlı tahminler elde edilememektedir. Ayrıca, HEEK zaman içinde hata teriminin ardışık bağımlılığını da dikkate almamaktadır (Wooldrige, 2002: 256). Söz konusu bu sakıncaların giderilmesi amacıyla 


\section{S.AĞAZADE - A.KARAKAYA - S. PERÇIN}

statik ve dinamik olmak üzere iki grupta sınıflanan panel veri analizi için özel tahminciler geliştirilmiştir.

Statik panel veri modellerinde, bağımlı değişkeni açıklamada bağımlı ve bağımsız değişkenin gecikmeli değerleri yer almaz. Dinamik panel veri modellerinde ise, bağımlı değişkeni etkileyen faktörler arasında, bağımsız değişken veya değişkenlerin gecikmeli değerleri olabileceği gibi, bağımlı değişkenin gecikmeli değerleri de yer alabilmektedir. İşte bu gecikmeli değerler analize dinamik nitelik kazandırmaktadır. Bu yönüyle dinamik panel veri analizi, yatay kesit veya zaman serisi yöntemlerinin ortaya koyamadığı, mikro ve makro dinamikleri ortaya koyabilmektedir (Bond, 2002: 1).

Dinamik panel veri analizi, ekonometri literatüründe, ilk olarak Hansen (1982) tarafindan geliştirilmiş olan Genelleştirilmiş Momentler Metodunu (GMM) temel almaktadır. Anderson ve Hsiao (1981 ve 1982) GMM'yi panel veriye uyarlamışlardır. Daha sonradan Arellano ve Bond (1991), Arellano ve Bover (1995) ve Blundell ve Bond (1998) tarafindan bu yöntem geliştirilmiş ve panel veri yazınında yazarların isimleriyle birlikte anılan GMM ve Sistem Genelleştirilmiş Momentler Metodu (SGMM) olarak geçmiştir.

GMM tahmin yönteminde öncelikle modelin birinci farkı alınıp, fark modelin araç değişken matrisi kullanılarak dönüştürülmektedir. Daha sonra dönüştürülmüş model Genelleştirilmiş En Küçük Kareler (GEKK) ile tahmin edilmektedir. Veri seti dengeli olmayan panel veri ya da birim sayısının zamandan az olduğu panel verilerde birinci fark dönüşümü zayıf kalmaktadır. Bu durumda doğrusal (orthogonal) sapmaları kullanan SGMM kullanılmaktadır. Böylece SGMM ile etkin araç değişken tahmincisi elde edilebilmektedir (Baltagi, 2005: 148). SGMM'de GMM deki cari dönemden 
bir önceki dönemin farkının alınması yerine, değişkenlerin tüm olası gelecek değerlerinin ortalamalarının farkı alınmaktadır. Böylece, Blundell ve Bond'a (2000) göre birinci farklar yönteminden kaynaklanan veri kaybı en aza indirilmektedir.

GMM tahmin yöntemi zamanın birim sayısından daha fazla olduğu panel veri setindeki değişkenler arası ilişkilerin tahmininde tercih edilmektedir. Dolayısıyla, birimin zamandan büyük olduğu panel veri setlerinde değişkenler arasındaki doğrusal ilişkinin ortaya konmasında da SGMM tahmin yöntemi tercih edilir. GMM ve SGMM'nin iki aşamalı tahmincileri de mevcuttur. Bağımsız değişkenlerin içsel değişken olduğu durumda iki aşamalı tahminlerden elde edilen bulgular daha tutarlı ve sapmasızdır. $\mathrm{Bu}$ çalışmanın veri setinde birim sayısı zamandan büyük olduğundan Arellano ve Bover (1995) ve Blundell ve Bond (1998) tarafından önerilen iki aşamalı SGMM tahmin yöntemi ile tahminler gerçekleştirilmiştir. Ayrıca küçük örneklem tahminlerindeki standart hataların sapmasız olması için Windmeijer'in (2005) tarafından önerilen dirençli standart hatalar kullanılmıştır. Söz konusu dirençli standart hataların hesaplanmasında Roodman (2009) tarafindan yazılan kod kullanılmıştır.

Çalışmada imalat sanayinin 24 endüstri kolunda risk ve performans arasındaki ilişki dinamik panel veri analiz yaklaşımıyla tahmin edilmiştir. İlgili ilişki aşağıdaki denklemde gösterilmiştir:

$$
\begin{array}{r}
\operatorname{RISK}_{i t}=\beta_{1} \text { RIS }_{i t-1}+\beta_{2} \text { PERFORMANS } \\
+\beta_{3}(\text { PERFORMANS } \\
t-1)+\varepsilon_{i t}
\end{array}
$$

Burada, $t$ ve $i$ sirasıyla zaman ve endüstri kolunu göstermektedir. Denklemdeki $R$ İSK $K_{i t-1}$ modele dinamik özellik katan bağımlı değişkenin bir dönem gecikmesidir. $R \dot{\mathrm{I}} S K_{i t} \mathrm{t}$ dönemi endüstri kolu riskini, $R \dot{\mathrm{I}} S K_{i t-1} \mathrm{t}-1$ dönemi endüstri kolu riskini, PERFORMANS $S_{i t-1} \mathrm{t}-1$ dönemi endüsri kolu 


\section{S.AĞAZADE - A.KARAKAYA - S. PERÇIN}

performansını, PERFORMANS $S_{t-1}$ t-1 dönemi imalat sanayi performansını ve $\varepsilon_{i t}$ denklemin hata terimini göstermektedir. Denklemdeki risk endüstri kollarındaki toplam, faaliyet ve finansal riski göstermektedir. Performans ise, hem endüstri kolları için hem de imalat sanayinin toplamı için net kârmarjı, aktif kârlılık oranı ve öz sermaye kârlılık oranı ile temsil edilmektedir.

\section{ARAŞTIRMA BULGULARI}

Araştırmanın bulguları örneklem genel özellikleri ve model değişkenleri arasındaki ilişkilerin sunulduğu tanımlayıcı istatistikler, birim kök testi ve model tahmin sonuçlarının verildiği risk ve performans arasındaki ilişki olmak üzere üç alt başlıkta aşağıda yer almaktadır.

\subsection{Tanımlayıcı İstatistikler}

Tablo 3 ve 4'de araştırmada kullanılan değişkenlere ait tanımlayıcı istatistikler yer almaktadır. Tablo 3'de endüstri düzeyinde risk ve performans değişkenlerinin ortalama ve standart sapmalarına yer verilmiştir. Risk değişkenlerinden iş riskini temsilen faaliyet kaldıracı derecesi satışlardaki belli bir değiş̧imin faiz ve vergi öncesi kârda nasıl bir değişime neden olduğunu, başka bir ifadeyle faiz ve vergi öncesi kârın satışlara ne derece duyarlı olduğunu gösterir. Faaliyet kaldıracı derecesi 2,1 hesaplanmıştır. Faiz ve vergi öncesi kârda satışların 2,1 katı değişim olmuştur. Bu satışlarda \%10 değiştiğinde faiz ve vergi öncesi kârın \%21 değiştiğini ifade etmektedir.

Finansal riski gösteren finansal kaldıraç derecesi faiz ve vergi öncesi karda belirli bir değişim olduğunda olağan kârın ne kadar değiştiğini, yani olağan kâr faiz ve vergi öncesi kâra ne kadar duyarlı olduğunu gösterir. Finansal kaldıraç derecesi 1,7 hesaplanmış ve olağan kârın faiz ve vergi 
Dokuz Eylül Üniversitesi İktisadi ve İdari Bilimler Fakültesi Dergisi Cilt:32, Sayl:1, Yll:2017, ss. 29-57

öncesi kârın 1,7 katı değişmiştir. $\mathrm{Bu}$ faiz ve vergi öncesi kâr \%10 değiştiğinde olağan kârın \%17 değiştiği anlamına gelir.

Toplam risk yani toplam kaldıraç derecesi satışlardaki değişimin olağan kârda nasıl bir değişime yol açtığını yani olağan kârın satışlara karşı duyarlılığını verir. Toplam kaldıraç derecesi ortalama olarak 3,6'dur. Olağan kârda satışların 3,6 katı değişim olmuştur. Bu bulgu satışlardaki \%10’luk bir değişim olduğunda olağan kârın \%36 değiştiğini gösterir.

Bulgular Türk İmalat Sanayi'nde inceleme döneminde toplam risk içerisinde iş riskinin finansal riskten daha fazla paya sahip olduğu elde edilmiştir. Dolayısıyla, aslında finansal riskten ziyade iş riskinin azaltılmasıyla Türk İmalat Sanayi'nin toplam riskin azaltılabileceği söylenebilir.

Performans göstergelerinden net kâr marjı ve aktif kârlılık oranı benzer biçimde \%3,6'dır. Öz sermaye kârlılık oranı yaklaşık \%8,5'dir. Satışlar ve aktifler üzerinden kârlılığın öz sermaye kârlılığından düşük hesaplanmıştır. Firmaların finansmanda öz sermaye yanında yüksek borçlanmaya başvurmalarının bir sonucu olarak firma kârlılığına nispeten hissedarların kârlılığı çok daha yüksek gerçekleşmiştir. Dolaysıyla, Türk İmalat Sanayi’nde hissedarların kârlılığı firma ve satış kârlılığından yüksektir.

Tablo 3. Değişkenlerin Ortalama ve Standart Sapması

\begin{tabular}{|l|l|l|}
\hline Değişkenler & Ortalama & Standart Sapma \\
\hline Toplam Kaldıraç Derecesi & 3,6018 & 8,4118 \\
\hline Faaliyet Kaldıracı Derecesi & 2,114 & 7,6232 \\
\hline Finansal Kaldıraç Derecesi & 1,7036 & 2,1149 \\
\hline Net Kar Marjı (\%) & 3,6913 & 4,8000 \\
\hline Aktif Karlılık Oranı (\%) & 3,6517 & 4,0360 \\
\hline Öz Sermaye Karlılık Oranı (\%) & 8,4877 & 9,4922 \\
\hline
\end{tabular}




\section{S.AĞAZADE - A.KARAKAYA - S. PERÇİN}

Tablo 4'de değişkenlerin korelasyonları yer almaktadır. Risk göstergelerinin kendi aralarındaki korelasyonları ile performans göstergelerinin kendi aralarındaki korelasyonları beklendiği gibi pozitif ve anlamlıdır. İş riski ile net kar marjı ve öz sermaye karlılık oranı arasındaki korelasyonlar negatif ve istatistiksel olarak anlamlıdır. Finansal risk ile performans göstergeleri arasındaki korelasyonlar ise anlamlı değildir. Toplam risk ile performans göstergeleri arasındaki korelasyonlar pozitif ve anlamlıdır. Risk ve performans göstergelerinin kendi içerisindeki yüksek korelasyonlar tutarlılığın bir işaretidir. İş riski arttı̆̆ında performansın azaldığı veya performans arttığında iş riskinin azaldığı buna karşın toplam riskle performansın aynı yönde değiştiği elde edilmiştir. Performansla risk arasındaki ilişkinin finansal riskten çok iş riski kaynaklı olduğu ortaya çıkmıştır. Dolayısıyla Türk İmalat Sanayi'nin performansta belirleyici olanın finansal riskten ziyade iş riski olduğu söylenebilir.

Tablo 4. Değişkenler Arası Korelasyonlar

\begin{tabular}{|c|c|c|c|c|c|c|}
\hline Değişkenler & TKD & FKD & FIKD & NKM & AKO & ÖSKO \\
\hline TKD & 1 & & & & & \\
\hline FKD & $0.2914^{* *}$ & 1 & & & & \\
\hline FİKD & $0.7392^{* * *}$ & $0.1002^{*}$ & 1 & & & \\
\hline NKM & $0.1600^{*}$ & $-0.1166^{*}$ & 0.0142 & 1 & & \\
\hline AKO & $0.1562^{*}$ & -0.0615 & 0.0025 & $0.9221^{* * *}$ & 1 & \\
\hline ÖSKO & $0.1625^{*}$ & $-0.1080^{*}$ & 0.0372 & $0.8789^{* * *}$ & $0.9576^{* * *}$ & 1 \\
\hline
\end{tabular}

Aşağılda Şekil 1-2'de değişkenlerin eğilimleri gösterilmiştir. Şekil 1'de risk göstergelerinin yıllar itibariyle sergilediği eğilim sunulmuştur. Finansal risk iş riskine kıyasla daha düşük ve istikrarlıdır. Bu durum, firmaların finansal riskten kaçınmasına rağmen iş riskine girmekten kaçınmadığını gösterir. Dolayısıyla, toplam risk, iş riskinden oluşmaktadır. 


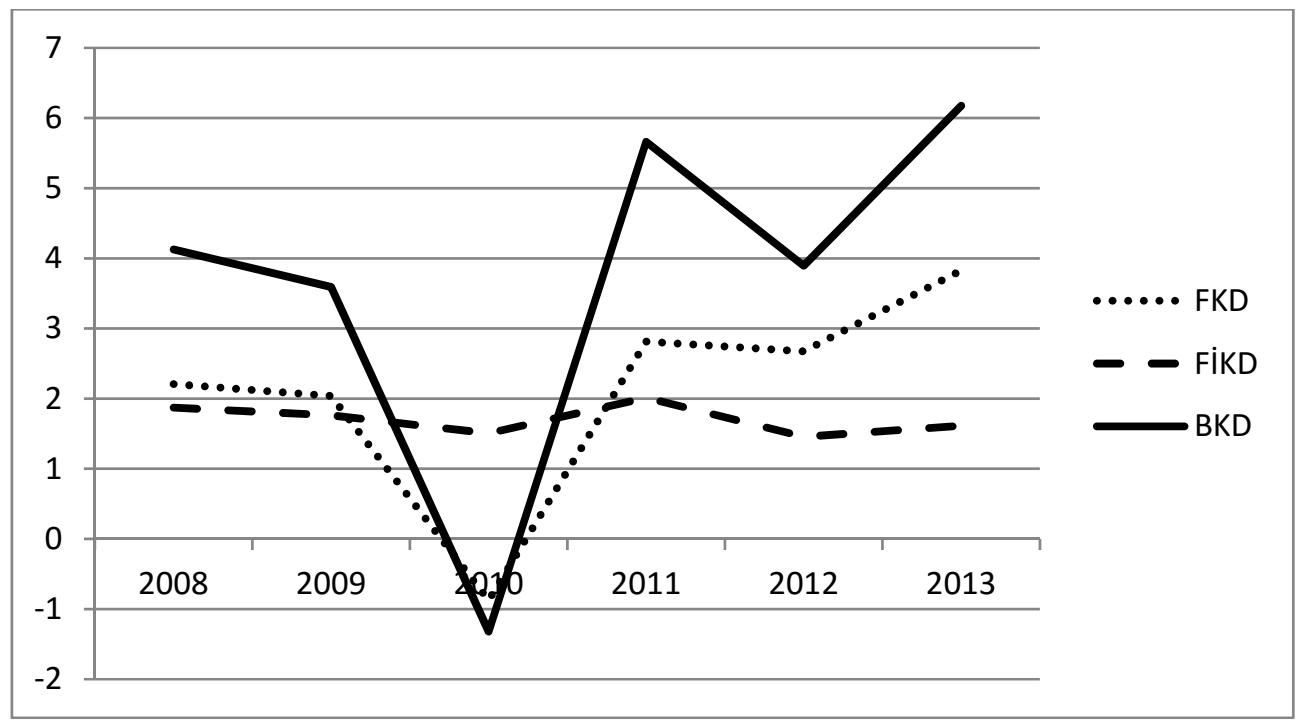

Şekil 1. Risk Göstergeleri

Şekil 2'de Türkiye'deki İmalat Sanayi'nin y1llar itibariyle performans değişkenleri olan net kâr marjı, aktif kârlılık oranı ve öz sermaye kârlılık oranının eğilimi ortaya konmuştur. Tüm performans göstergelerinin benzer biçimde hareket ettiği ve eğilimlerinin "ters W" şeklinde olduğu tespit edilmiştir. Performans göstergelerinin sırasıyla 2008 yılında düşük, 2009 ve 2010 y1llarında yüksek, 2011 yılında düşük, 2012 yıllında yüksek ve son olarak 2013 yılında düşük gerçekleşmiştir. Performansta dalgalanmalar olmuş ve yıllar itibariyle inişler ve çıkışlar birbirini izlemiştir. $\mathrm{Bu}$ bulgu, inceleme döneminde Türk İmalat Sanayi'nde performansın oynak bir yapıya sahip olduğunu gösteriyor. Bu oynak yapıya aslında küresel ekonomide yaşanan finansal krizin neden olduğunu söylemek yanlış olmayacaktır. 
S.AĞAZADE - A.KARAKAYA - S. PERÇİN

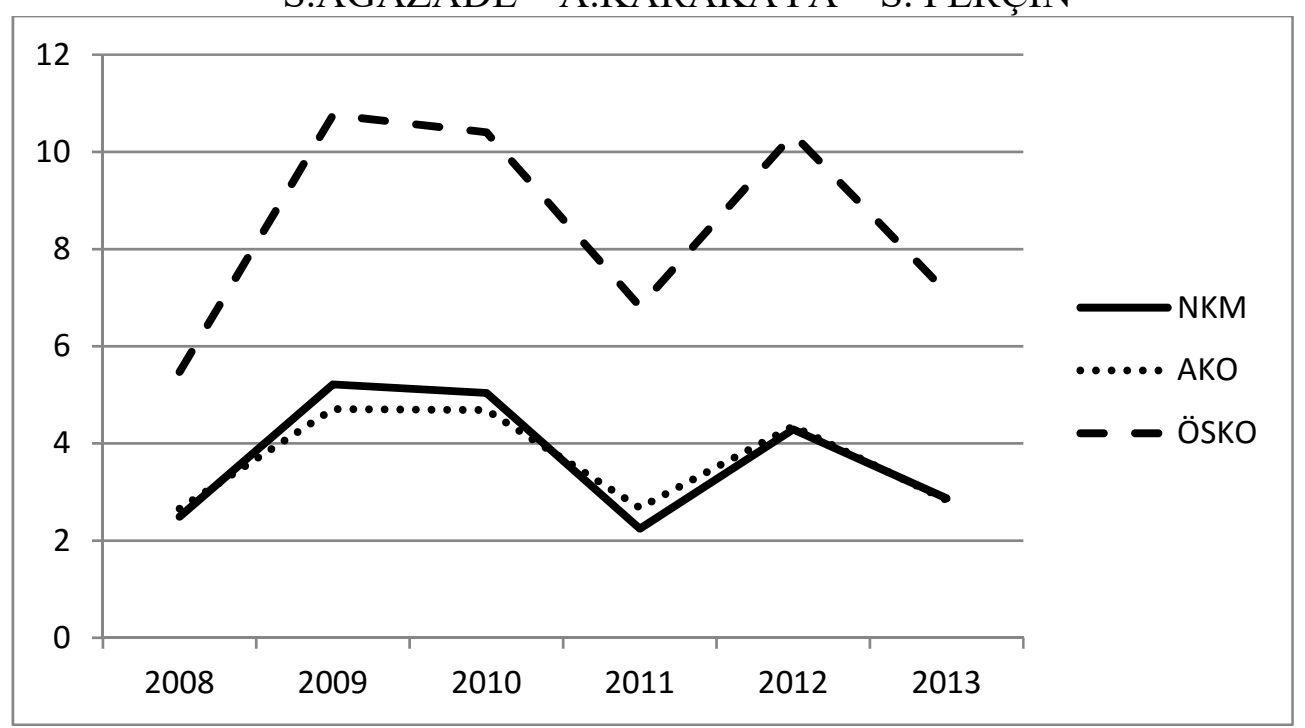

Şekil 2. Performans Göstergeleri (\%)

\subsection{Panel Birim Kök Testi Bulguları}

Zaman serisi analizlerinde olduğu gibi panel veri analiz tahminlerinde de sahte regresyonla karşılaşmak istenmez. Bu amaçla değişkenlerin birim kök testi yapılıp, durağan oldukları tespit edilir. Panel verilerin birim kök testi için geliştirilmiş panel birim kök testleri bulunmaktadır. Panel birim kök testleri genel olarak birinci ve ikinci kuşak biçiminde iki grupta ele alınır. Birinci kuşak panel birim kök testleri birimlerin bağımsız, ikinci kuşak panel birim kök testleri ise birimlerin bağımlı olduğunu varsaymaktadır. Birinci kuşak panel birim kök testleri de, kendi içerisinde iki bölüme ayrılır. Bunlardan, birinci gruptaki panel birim kök testleri otokorelasyonun birimden birime değişmediğini, buna karşın ikinci grup ise değiştiğini varsaymaktadır.

Çalışmada birimlerin bağımlılığı birim bağımlılığı testlerinden Pesaran (2004) testi ile gerçekleştirilmiştir. Aşağıdaki Tablo 5'deki risk modelleri tahminlerinin Pesaran Test sonuçları birimlerin bağımsız olduğunu gösterdiğinden birinci kuşak panel birim kök testlerinin uygun olduğuna 
Dokuz Eylül Üniversitesi İktisadi ve İdari Bilimler Fakültesi Dergisi Cilt:32, Sayl:1, Yll:2017, ss. 29-57

karar verilmiştir. İlaveten birimler farklı sektörler olduğundan farklı sektörlerde yapılan işin doğası gereği farklılaşacağı kabulünden hareketle otokorelasyonun birimler için sabit olmayacağı varsayımının daha isabetli olacağı düşünülmüştür. Dolayısıyla birinci kuşak panel birim kök testleri içerisindeki ikinci grup testlerle birim kök testi gerçekleştirilmiştir. İkinci grup panel birim kök testleri Im, Peseran ve Shin (2003) (IPS) testi ve Fisher testleridir. IPS testi tek bir istatistiğe Fisher testleri ise birden fazla istatistiğin kombinasyonları üzerine kurulu olduğundan çalışmada Fisher testleri tercih edilmiştir.

Tablo 5. Pesaran Birimlerin Bağımlılı̆̆ı Test Sonuçları

\begin{tabular}{|c|c|c|}
\hline \multicolumn{2}{|c|}{ Risk Modelleri } & İstatistik \\
\hline \multirow{3}{*}{ Toplam Risk Modeli } & Toplam Risk Denklemi 1 & 1,209 \\
\hline & Toplam Risk Denklemi 2 & 1,954 \\
\hline & Toplam Risk Denklemi 3 & 1,749 \\
\hline \multirow{3}{*}{ Faaliyet Risk Modeli } & Faaliyet Riski Denklemi 1 & 1,448 \\
\hline & Faaliyet Riski Denklemi 2 & 1,655 \\
\hline & Faaliyet Riski Denklemi 3 & 1,298 \\
\hline \multirow{3}{*}{ Finansal Risk Modeli } & Finansal Risk Denklemi 1 & 1,532 \\
\hline & Finansal Risk Denklemi 2 & 1,944 \\
\hline & Finansal Risk Denklemi 3 & 1,536 \\
\hline
\end{tabular}

Fisher panel birim kök testleri Fisher ADF ve Fisher Philips-Perron (PP) olmak üzere ikiye ayrilır. Fisher ADF testi zaman serileri birim kök testlerinden ADF birim kök testini her birime uygulamaktadır. Benzer biçimde, Fisher PP testi de zaman serileri birim kök testlerinden biri olan Philips-Perron (PP) birim kök testini her birim için uygulamaktadır (Choi, 2001). 
S.AĞAZADE - A.KARAKAYA - S. PERÇIN

Tablo 6. Fisher Phillips-Perron Panel Birim Kök Testi Sonuçları

\begin{tabular}{|c|c|c|}
\hline Değişkenler & Düzeltilmiş Ters $X^{2}$ & Durum \\
\hline Toplam Kaldıraç Derecesi $i_{t}$ & $54,3232^{* * *}$ & Düzey durağandır \\
\hline Faaliyet Kaldıracı Derecesi $i_{t}$ & $15,3323^{* * *}$ & Düzey durağandır \\
\hline Finansal Kaldıraç Derecesi $i_{t}$ & $56,0408^{* * *}$ & Düzey durağandır \\
\hline Net Kar Marj $1_{\mathrm{t}}$ & $26,4827^{* * *}$ & Düzey durağandır \\
\hline Aktif Karlılık Oran1 $_{\mathrm{t}}$ & $27,8372^{* * *}$ & Düzey durağandır \\
\hline Öz Sermaye Karlılık Oranıt & $23,8753^{* * *}$ & Düzey durağandır \\
\hline
\end{tabular}

${ }^{*},{ }^{* *}$ ve ${ }^{* * *}$ sirasıyla $0.10,0.05$ ve 0.01 düzeyinde istatistiksel anlamlılıkları göstermektedir.

Fisher P-P testinin $\mathrm{P}, \mathrm{Z}, \mathrm{L}^{*}$ ve $\mathrm{P}_{\mathrm{m}}$ istatistiklerinin tamamı aynı sonucu verdiğinden bunlardan sadece $\mathrm{P}_{\mathrm{m}}$ istatistiğini gösteren Düzeltilmiş Ters $X^{2}$ değerleri yukarıdaki Tablo 6'da raporlanmıştır. $P_{m}$ istatistiğine göre çalışmanın risk ve performans değişkenlerinin tamamının birinci mertebede birim kök içermediği, yani tüm değişkenlerin birinci mertebede durağan olduğu sonucuna varılmıştır.

\subsection{Risk ve Performans Arasındaki İlişki}

Aşağıdaki Tablo 7-9'da sunulan İki Aşamalı SGMM tahmincisinden elde edilen bulgularda, modellerin genel anlamlılığını sınamak için yapılan Wald test sonuçlarına bakıldığında, tüm modeller anlamlıdır. İlaveten tahmin edilen modellerin etkinliği için araç değişkenlerin doğru seçilmesi gerekmektedir. Bunun için geliştirilen testler mevcuttur. Bunlar, otokorelasyon testleri, Sargan Testi, Hansen Testi ve Fark Hansen testidir. Modellerle ilgili, birinci mertebe otokorelasyonun varlığının testinde Arellano ve Bond'un (1991) otokorelasyon (AR1) testinde otokorelasyonun olmadığ 1 boş hipotezinin testlerinde, boş hipotez kabul edilmiştir. Ardından Arellano ve Bond'un (1991) ikinci mertebe otokorelasyon (AR2) testinde otokorelasyonun olmadığı boş hipotezinin testinde, boş hipotez ret edilmiştir. Böylece, modelin uygunluğu için gereken birinci mertebe 
Dokuz Eylül Üniversitesi İktisadi ve İdari Bilimler Fakültesi Dergisi Cilt:32, Sayl:1, Yll:2017, ss. 29-57

otokorelasyonun olmas1 ve ikinci mertebe otokorelasyonun olmamas1 koşulu sağlanmıştır. Son olarak, modellerden elde edilen araç değişkenlerin geçerliliği için yapılan testlerde dirençsiz olan Sargan Testi anlamlı olmasına rağmen, direçli olan Hansen Testi ve Fark Hansen Testi anlamsız bulunmuştur. $\mathrm{Bu}$ test sonuçları, SGMM yöntemiyle yapılan risk modelinin tahmininde kullanılan araç değişkenler regresyonunda kullanılan araç değişkenlerin geçerli ve modelin uygun olduğunu göstermiştir. Dolayısıyla, dinamik risk modelinin genel anlamlılık, otokorelasyon ve araç değişkenler regresyonu ile ilgili koşulları sağlanmıştır.

Tablo 7. Toplam Kaldıraç Derecesi (Toplam Risk) Modeli Çözüm Sonuçları

\begin{tabular}{|c|c|c|c|}
\hline & Denklem 1 & Denklem 2 & Denklem 3 \\
\hline Değişkenler & $\mathrm{TKD}_{\mathrm{t}}$ & $\mathrm{TKD}_{\mathrm{t}}$ & $\mathrm{TKD}_{\mathrm{t}}$ \\
\hline $\mathrm{TKD}_{\mathrm{t}-1}$ & $0.1837^{* * *}$ & $0.1914^{* * *}$ & $0.2105^{* * *}$ \\
\hline $\mathrm{NKM}_{\mathrm{t}-1}$ & $0.3852^{* * *}$ & & \\
\hline $\mathrm{AKO}_{\mathrm{t}-1}$ & & $0.5434^{* * *}$ & \\
\hline $\mathrm{ÖSKO}_{\mathrm{t}-1}$ & & & $0.2202^{* * *}$ \\
\hline İmalat Sanayi NKM ${ }_{\mathrm{t}-1}$ & $0.5412^{* * *}$ & & \\
\hline $\begin{array}{l}\text { Imalat Sanayi } \mathrm{AKO}_{\mathrm{t}-1} \\
\end{array}$ & & $0.3069^{* * *}$ & \\
\hline İmalat Sanayi ÖSKO $\mathrm{t}_{\mathrm{t}-1}$ & & & $0.1226^{* * *}$ \\
\hline Wald Test & $1589.25^{* * *}$ & $8463.98^{* * *}$ & $5518.03^{* * *}$ \\
\hline AR1 Test & $-2.46^{* *}$ & $-2.54^{* *}$ & $-2.53^{* *}$ \\
\hline AR2 Test & -1.17 & -1.15 & -1.17 \\
\hline Sargan Test & $59.83^{* * *}$ & $58.65^{* * *}$ & $61.85^{* * *}$ \\
\hline Hansen Test & 13.93 & 25.93 & 13.49 \\
\hline Fark Hansen Test & 4.66 & 5.85 & 4.93 \\
\hline
\end{tabular}

${ }^{*},{ }^{* *}$ ve ${ }^{* * *}$ sirasıyla $0.10,0.05$ ve 0.01 düzeyinde istatistiksel anlamlılıkları göstermektedir.

Tablo 7'de endüstri toplam riski olan Toplam Kaldıraç Derecesinin kendisinin bir dönem gecikmesinden, endüstri kolu performansının bir 


\section{S.AĞAZADE - A.KARAKAYA - S. PERÇIN}

dönem gecikmesinden ve imalat sanayi performansının bir dönem gecikmesinden pozitif yönde etkilendiği görülmektedir.

Tablo 8'de endüstri iş riskini temsilen Faaliyet Kaldıracı Derecesini kendisinin bir dönem gecikmesi ve endüstri performansının bir dönem gecikmesinin negatif yönde etkilediği ortaya konmuştur. Endüstri iş riski imalat sanayi performansının bir dönem gecikmesinden negatif yönde etkilenmiştir.

Tablo 9'da endüstri finansal riskini temsilen Finansal Kaldıraç Derecesinin kendisinin bir dönem gecikmesinden ve endüstri performans göstergelerinin bir dönem gecikmesinden pozitif etkilendiği görülmektedir. Endüstri finansal riskinin imalat sanayi performansının bir dönem gecikmesinden pozitif yönde etkilendiği tespit edilmiştir.

Tablo 8: Faaliyet Kaldıracı Derecesi (İş Riski) Modeli Çözüm Sonuçları

\begin{tabular}{|l|l|l|l|}
\hline \multirow{2}{*}{ Değişkenler } & Denklem 1 & Denklem 2 & Denklem 3 \\
\hline & $\mathrm{FKD}_{\mathrm{t}}$ & $\mathrm{FKD}$ & $\mathrm{FKD}_{\mathrm{t}}$ \\
\hline $\mathrm{FKD}_{\mathrm{t}-1}$ & $-0.0099^{* * *}$ & $-0.0376^{* * *}$ & $-0.0244^{* * *}$ \\
\hline $\mathrm{NKM}_{\mathrm{t}-1}$ & $-0.4818^{* * *}$ & & \\
\hline $\mathrm{AKO}_{\mathrm{t}-1}$ & & $-0.5065^{* * *}$ & \\
\hline ÖSKO $\mathrm{t}-1$ & & & $-0.1831^{* * *}$ \\
\hline İmalat Sanayi $\mathrm{NKM}_{\mathrm{t}-1}$ & $1.1381^{* * *}$ & & \\
\hline İmalat Sanayi $\mathrm{AKO}_{\mathrm{t}-1}$ & & $0.9606^{* * *}$ & \\
\hline İmalat Sanayi ÖSKO $\mathrm{t}-1$ & & & $0.4518^{* * *}$ \\
\hline & & & \\
\hline Wald Test & $14900.00^{* * *}$ & $36096.80^{* * *}$ & $39997.58^{* * *}$ \\
\hline AR1 Test & $-2.03^{* *}$ & $-2.02^{* *}$ & $-2.03^{* *}$ \\
\hline AR2 Test & 1.03 & 1.02 & 1.01 \\
\hline Sargan Test & $43.10^{* * *}$ & $44.42^{* * *}$ & $42.92^{* * *}$ \\
\hline Hansen Test & 18.07 & 19.80 & 20.08 \\
\hline Fark Hansen Test & 15.14 & 15.10 & 15.99 \\
\hline
\end{tabular}


Dokuz Eylül Üniversitesi İktisadi ve İdari Bilimler Fakültesi Dergisi Cilt:32, Sayl:1, Yll:2017, ss. 29-57 ${ }^{*},{ }^{* *}$ ve ${ }^{* * *}$ sirasıyla $0.10,0.05$ ve 0.01 düzeyinde istatistiksel anlamlılıkları göstermektedir. Tablo 9: Finansal Kaldıraç Derecesi (Finansal Risk) Modeli Çözüm Sonuçları

\begin{tabular}{|c|c|c|c|}
\hline & Denklem 1 & Denklem 2 & Denklem 3 \\
\hline Değişkenler & $\mathrm{FiKD}_{\mathrm{t}}$ & $\mathrm{FiKD}_{\mathrm{t}}$ & $\mathrm{FiKD}_{\mathrm{t}}$ \\
\hline FiKD $_{\mathrm{t}-1}$ & $0.0511^{* * *}$ & $0.0720^{* * *}$ & $0.0691^{* * *}$ \\
\hline $\mathrm{NKM}_{\mathrm{t}-1}$ & $0.1210^{* *}$ & & \\
\hline $\mathrm{AKO}_{\mathrm{t}-1}$ & & $0.1511^{* * *}$ & \\
\hline ÖSKO $_{\mathrm{t}-1}$ & & & $0.0862^{* * *}$ \\
\hline İmalat Sanayi NKM ${ }_{\mathrm{t}-1}$ & $0.2896^{* * *}$ & & \\
\hline İmalat Sanayi $\mathrm{AKO}_{\mathrm{t}-1}$ & & $0.2024^{* * *}$ & \\
\hline İmalat Sanayi ÖSKO & & & $0.0707^{* * *}$ \\
\hline Wald Test & $2368.17^{* * *}$ & $1341.28^{* * *}$ & $754.72^{* * *}$ \\
\hline AR1 Test & $-2.06^{* *}$ & $-2.03^{* *}$ & $-2.51^{* *}$ \\
\hline AR2 Test & -0.98 & -0.86 & -0.88 \\
\hline Sargan Test & $21.06^{*}$ & $20.55^{*}$ & 18.38 \\
\hline Hansen Test & 10.29 & 13.46 & 15.19 \\
\hline Fark Hansen Test & 4.28 & 4.79 & 5.52 \\
\hline
\end{tabular}

${ }^{*},{ }^{* *}$ ve ${ }^{* * *}$ sirasıyla $0.10,0.05$ ve 0.01 düzeyinde istatistiksel anlamlılıkları göstermektedir.

\section{SONUÇ VE DEĞERLENDİRME}

Geleneksel finans teorisinin risk ve performans arasında pozitif ilişki öngörmesine karşın Bowman'ın (1980 ve 1984) çalışmaları ilişkinin negatif olabileceğine ilişkin önemli kanttlar sunmuştur. Kahneman ve Tversky (1979) tarafindan geliştiren beklenti teorisi ve Cyert ve March'ın (1963) davranışsal firma teorisi de negatif risk ve performans ilişkisi için teorik temel niteliğindedir. Bu ilişkinin şekli, Andersen ve diğerlerinin (2007) de ifade ettiği gibi endüstri dalının karakteristik özelliği, rekabetçi yapı ve firmaların bu çevresel koşullara cevap verebilme kabiliyeti gibi farklı değişkenlere göre farklılık gösterebilir. 


\section{S.AĞAZADE - A.KARAKAYA - S. PERÇİN}

Bu çalışmada, Arellano ve Bover (1995) ve Blundell ve Bond (1998) tarafından geliştirilen İki Aşamalı Sistem Genelleştirilmiş Moment Metodu ve 2008-2013 dönemi NACE Rev.2 sinıflamasına göre Türk İmalat Sanayi endüstri kollarına ait veriler kullanılarak, değişkenlere ait farklı göstergelerle performansın risk alma tutumu üzerindeki etkisi araştırılmıştır. Çalışmada risk göstergesi olarak toplam kaldıraç derecesi, faaliyet kaldıraç derecesi ve finansal kaldıraç derecesi kullanılmıştır. Performans değişkeni göstergeleri ise net kâr marjı, aktif kârlılık oranı ve öz sermaye kârlılık oranlarıdır. Analize ait bulgular; performansın risk göstergesi olan toplam kaldıraç derecesi ve finansal kaldıraç derecesini pozitif; faaliyet kaldıracı derecesini ise negatif yönde etkilediği biçimindedir. Bu sonuçlara göre, Türk İmalat Sanayi'nde toplam risk ve finansal risk söz konusu olduğunda geleneksel teorinin, buna karşın iş riski dikkate alındığında ise davranışsal firma teorisi veya beklenti teorisinin öngörülerinin geçerli olduğu ortaya çıkmaktadır.

$\mathrm{Bu}$ sonuca göre, Türk İmalat Sanayi'nde risk ve performans arasındaki ilişki riskin türüne göre farklılık göstermektedir. Bu durum, firmaların sadece üstlendikleri riskin düzeyine değil aynı zamanda riskin türüne de baktıkları anlamına gelmektedir. Buna göre, söz konusu risk finansal risk olduğunda firma yöneticileri performans doğrultuşla aynı doğrultuda risk üstlenir. Buna karşın iş riski söz konusu olduğunda ise performansla ters yönde risk alındığı görülmektedir. Buradan anlaşıldığı gibi, performans azaldığında firmalar sabit faaliyet giderlerini artırmak suretiyle satışlarını ve kârlarını artırmaya çalışırlar. Esasen borçlanma sonucunda oluşan finansal risk, genellikle bankalar tarafından kontrollü biçimde, başarılı ve yüksek performansa sahip firmalara sağlandığından, hem performansla paralel hem de sinırlidir. 


\section{KAYNAKÇA}

AL MANASEER, M. F. A., AL-HINDAWI, R. M., AL-DAHIYAT, M. A., SARTAWI, I. I. (2012), "The Impact of Corporate Governance on the Performance of Jordanian Banks", European Journal of Scientific Research, 67(3), 349-359.

ANDERSEN, T. J., DENRELL, J., BETTIS, R. A. (2007), "Strategic Responsiveness and Bowman's Risk-return Paradox", Strategic Management Journal, 28(4), 407-429.

ANDERSON, T. W., HSIAO, C. (1981), "Estimation of Dynamic Models with Error Components", Journal of the American Statistical Association, 76(375), 598606.

ANDERSON, T. W., HSIAO, C. (1982), "Formulation and Estimation of Dynamic Models Using Panel Data", Journal of Econometrics, 18, 47-82.

ARELLANO M., BOND, S. (1991), "Some Tests of Specification for Panel: Monte Carlo Evidence and An Application to Employment Equations", Review of Economic Studies, 58, 277-297.

ARELLANO M., BOVER, O. (1995), "Another Look at the Instrumental Variable Estimation of Error-Components Models", Journal of Econometrics, 68, 29-51.

BALTAGI, B. H. (2005), Econometric Analysis of Panel Data, Third Edition, John Wiley\&Sons, Ltd., England.

BLUNDELL R., BOND S. (1998), "Initial Conditions and Moment Restrictions in Dynamic Panel Data Models", Journal of Econometrics, 87, 115-143.

BLUNDELL, R., BOND, S. (2000), "GMM Estimation with Persistent Panel Data: An Application to Production Functions", Econometric Reviews, 19, 321340 .

BOND, S. (2002), "Dynamic Panel Data Models: A Guide to Micro Data Methods and Practice", CEMMAP Working Paper, No: Cwp0209, 1-36.

BOWMAN, E. H. (1980), “A Risk-Return Paradox for Strategic Management”, Sloan Management Review, 21, 17-31.

BOWMAN, E. H. (1984), "Content Analysis of Annual Reports for Corporate Strategy and Risk", Strategic Managemen Interfaces, 14(1) 61-71.

BROMILEY, P. (1991), "Testing a Casual Model of Corporate Risk Taking and Performance", Academy of Management Journal, 34(1), 37-59. 


\section{S.AĞAZADE - A.KARAKAYA - S. PERÇİN}

CHARI, A., CHEN, W., DOMINGUEZ, K. M. E. (2012), "Foreign Ownership and Firm Performance: Emerging Market Acquisitions in the United States", IMF Economic Review, 60(1), 1-42.

CHOI, I. (2001), "Unit Root Tests for Panel Data", Journal of International Money and Finance, 20, 249-272.

CORE, J. E., HOLTHAUSEN, R. W., LARCKER, D. F. (1999), "Corporate Governance, Chief Executive Officer Compensation, and Firm Performance" Journal of Financial Economics, 51, 371-406.

CYERT, R., MARCH, J. (1963), A Behavioral Theory of the Firm, Prentice Hall Inc., New Jersey, USA.

DE YOUNG, R., ROLAND, K. P. (1999), Product Mix and Earnings Volatility at Commercial Banks: Evidence from a Degree of Leverage Model, Federal Reserve Bank of Chicago, Working Papers Series Research Department, (WP-99$6)$.

DEEPHOUSE, D. L. WISEMAN, R. M. (2000), "Comparing Alternative Explanations for Accounting Risk-Return Relations", Journal of Economic Behavior \& Organization, 42 (4), 463-482.

DUGAN, M. T., SHRIVER, K. A. (1992), "The Effects of Estimation Period, Industry, and Proxy on the Calculation of the Degree of Operating Leverage," The Financial Review, 24, 309-321.

FISHER, I. N., HALL, G. R. (1969), "Risk and Corporate Rates of Return", The Quarterly Journal of Economics, 83(1), 79-92.

FLETCHER, J. (2000), "On the Conditional Relationship between Beta and Return in International Stock Returns", International Review of Financial Analysis, 9(3), 235-245.

FRAQUELLI, G., VANNONI, D. (2000), "Multidimensional Performance In Telecommunications, Regulation And Competition: Analysing The European Major Players", Information Economics and Policy, 12, 27-46.

GOODING, R. Z., GOEL, S., WISEMAN, R. M. (1996), "Fixed Versus Variable Reference Points in the Risk-Return Relationship", Journal of Economic Behavior and Organization, 29(2), 331-350.

HANSEN, G. S., WERNERFELT, B. (1989), "Determinants of Firm Performance: The Relative Importance of Economic and Organizational Factors", Strategic Management Journal, 10(5), 399-411. 
HANSEN, L.P. (2002), "Large Sample Properties of Generalized Method of Moments Estimators", Econometrica, 50, 1029-1054.

HOQUE, Z., JAMES, W. (2000), "Linking Balancing Scorecard Measures to Size and Market Factors: Impact of Organizational Performance", Journal of Accounting Management Research, 12, 1-17.

HSIAO, C. (2003), Analysis of Panel Data, Second Edition, Cambridge University Press, United Kingdom.

IM, K. S., PESARAN, M. H., SHIN, Y. (2003), "Testing for Unit Roots in Heterogeneous Panels", Journal of Econometrics, 115, 53-74.

ITTNER, C. D., LARCKER, D. F., RANDALL, T. (2003), "Performance Implications of Strategic Performance Measurement in Financial Services Firms", Accounting, Organizations and Society, 28, 715-741.

ITTNER, C. D., LARCKER, D. F. (1997), "Quality Strategy, Strategic Control Systems, and Organizational Performance", Accounting Organizations and Society, 22(4), 293-314.

KAHNEMAN, D., TVERSKY, A. (1979), "Prospect Theory: An Analysis of Decision under Risk", Econometrica, 47(2), 263-292.

KARACA, S. S., EKŞI, İ. H. (2012), "The Relationship between Ownership Structure and Firm Performance: An Empirical Analysis over Istanbul Stock Exchange (ISE) Listed Companies", International Business Research, 5(1), 172181.

LEV, B. (1974), "On the Association between Operating Leverage and Risk", Journal of Financial and Quantitative Analysis, 9, 627-641.

LIN, C. (2011), “An Examination of Board and Firm Performance: Evidence from Taiwan", The International Journal of Business and Finance Research, 5(4), $17-35$.

LORD, R. A. (1998), "Properties of Time Series Estimates of Degree of Leverage Measures", The Financial Review, 33, 69-84.

MANDELKER, G., RHEE, S. G. (1984), "The Impact of the Degree of Operating and Financial Leverage on Systematic Risk of Common Stock", Journal of Financial and Quantitative Analysis, 19, 45-57.

MURPHY, K. J. (2001), "Performance Standards in Incentive Contracts", Journal of Accounting and Economics, 30, 245-278. 


\section{S.AĞAZADE - A.KARAKAYA - S. PERÇİN}

O'BRIEN, T., VANDERHEIDEN, P. (1987), "Empirical Measurement of Operating Leverage for Growing Firms", Financial Management, 16, 45-53.

OBIYO, O. C., LENEE, L. T. (2011), "Corporate Governance and Firm Performance in Nigeria", International Journal of Research in Commerce and Management, 1(4), 1-12.

PARK, A., YANG, D., SHI, X., JIANG, Y. (2009), "Exporting and Firm Performance: Chinese Exporters and The Asian Financial Crisis", NBER Working Paper Series, National Bureau of Economic Research, 1-50.

PESARAN, M. H. (2004), "General Diagnostic Tests for Cross Section Dependence in Panels", University of Cambridge, Faculty of Economics, Cambridge Working Papers in Economics No: 0435.

ROODMAN, D. (2009), "How to Do xtabond2: An Introduction to "Difference" and "System" GMM in Stata", The Stata Journal, 9(1), 86-136.

WINDMEIJER F. (2005), "A Finite Sample Correction for The Variance of Linear Efficient Two-Step Gmm Estimator", Journal of Econometrics, 126(1), 2551 .

WOOLDRIDGE, J. M. (2002), Econometric Analysis of Cross Section and Panel Data, The MIT Press, England.

YASSER, Q. R., ENTEBANG, H., MANSOR, S. A. (2011), "Corporate governance and firm performance in Pakistan: The case of Karachi Stock Exchange (KSE) -30", Journal of Economic and International Finance, 3(8), 482491. 